\title{
FRACTURE-DIASTASIS OF THE INFERIOR TIBIO-FIBULAR JOINT
}

\author{
C. L. Colton, London, England \\ From the Bristol Royal Infirmary, Bristol
}

Diastasis of the inferior tibio-fibular joint has been recognised as a component of fracturedislocations of the ankle since the early nineteenth century (Dupuytren 1819, Astley Cooper 1822, Maisonneuve 1840). It was mentioned briefly by Petit as early as 1726 . The present concept is that diastasis of the inferior tibio-fibular joint occurs only in association with indirect fractures of the fibular shaft above the level of the syndesmosis (Fig. 1), with the very rare exception of such a diastasis occurring without a fibular fracture (Salisbury Woods 1942, Bosworth 1947).

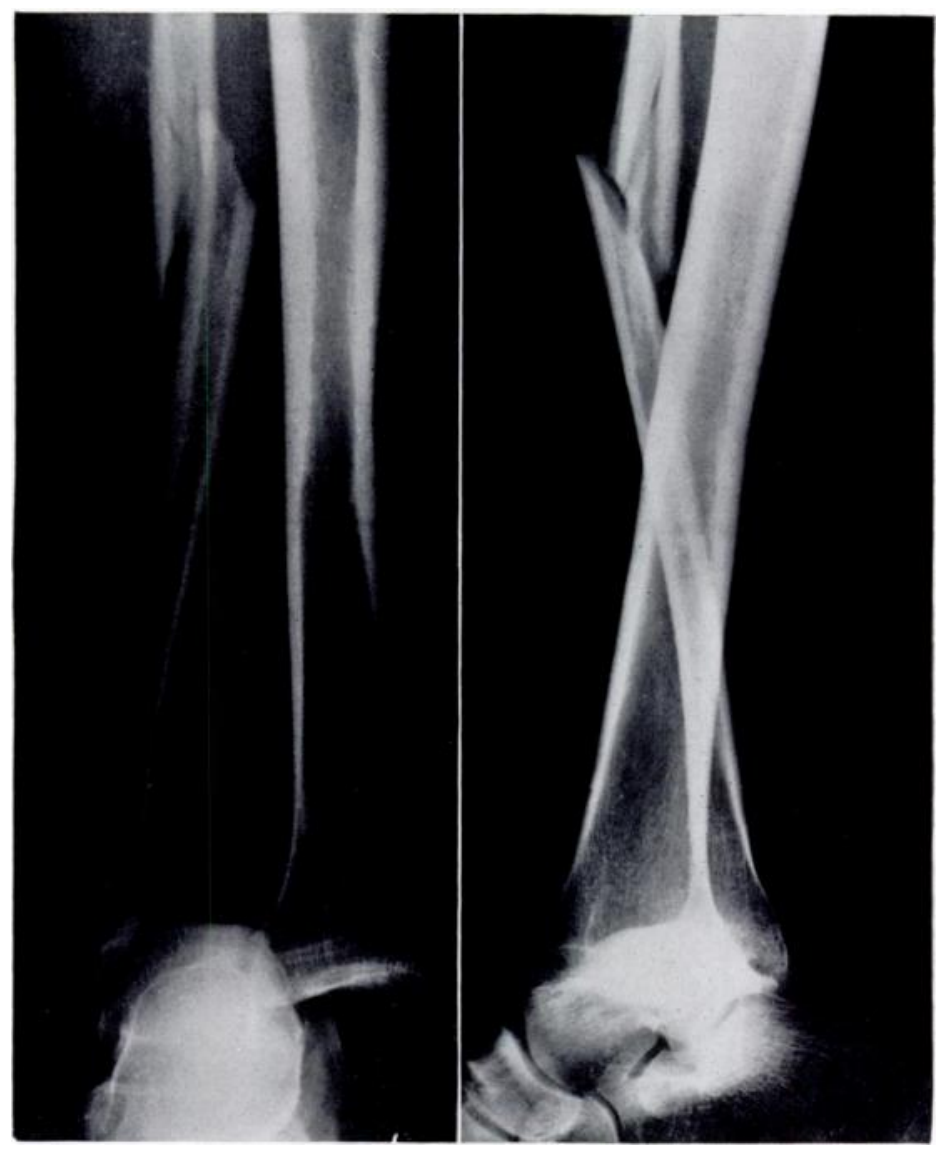

FIG. 1

Example of a high Dupuytren's fracture-dislocation showing an indirect fibular shaft fracture occurring above the disrupted inferior tibiofibular joint.

The low oblique fracture of the fibula, the plane of which passes forwards and downwards to the level of the ankle joint at its antero-inferior extremity (Fig. 2), so commonly seen and referred to as the " mixed oblique" fibular fracture (Ashhurst and Bromer 1922), has never been thought to be associated with inferior tibio-fibular diastasis. Bonnin (1950) stressed this point, and Iselin and Vellis (1961) categorically stated: "le diastasis intertibio-péronier n'éxiste pas dans les fractures malléolaires basses." So emphatic were these authors on 
this point, that for bimalleolar ankle fractures with widening of the mortise, where the lateral lesion was a mixed, oblique, fibular fracture, they coined the title " diastasis intrapéronier." This has been translated as intraosseous diastasis (Burwell and Charnley 1965).

Iselin's statement is not entirely correct, and this paper records seven cases of true inferior tibio-fibular diastasis associated with classical mixed oblique fractures of the fibula.

\section{CASE REPORTS}

Case 1-A fifty-year-old postman injured his right ankle in a fall from a bicycle. Radiographs showed a displaced oblique fracture of the lower fibula, its lower limit being level with the tibial articular surface. The medial ligament was ruptured as well (Fig. 3). The fracture-dislocation was reduced and the leg immobilised in good position in a below-knee plaster. Radiographs taken four days later showed that the original good reduction had been maintained (Fig. 4), and seven weeks after the injury the plaster was removed. Radiographs at that time showed the fibula to be united in a perfect position (Fig. 5) and the

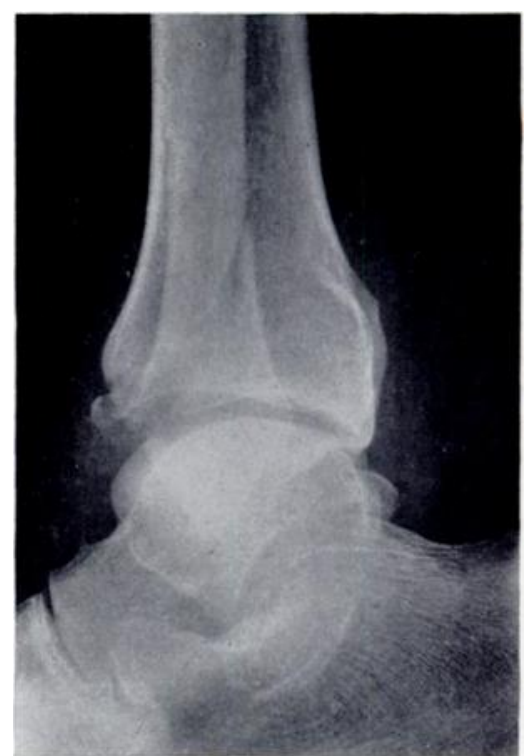

FIG. 2

A classical " mixed oblique" fibular fracture: occurring alone, this is a stable injury invariably undisplaced and usually only readily discernible on lateral radiographs of the ankle joint. patient was allowed to walk. Radiographs taken seven weeks later, however, showed clearly that a previously unrecognised diastasis of the inferior tibio-fibular joint had recurred, with a stress fracture above the united, original fibular fracture (Fig. 6). There had been no further injury.

Case 2-A forty-seven-year-old woman slipped on a grassy slope and injured her right ankle. She sustained an oblique fracture of the lower fibula, a traction fracture of the medial malleolus, and lateral rotation dislocation of the ankle joint (Fig. 7). At operation the fibular fracture

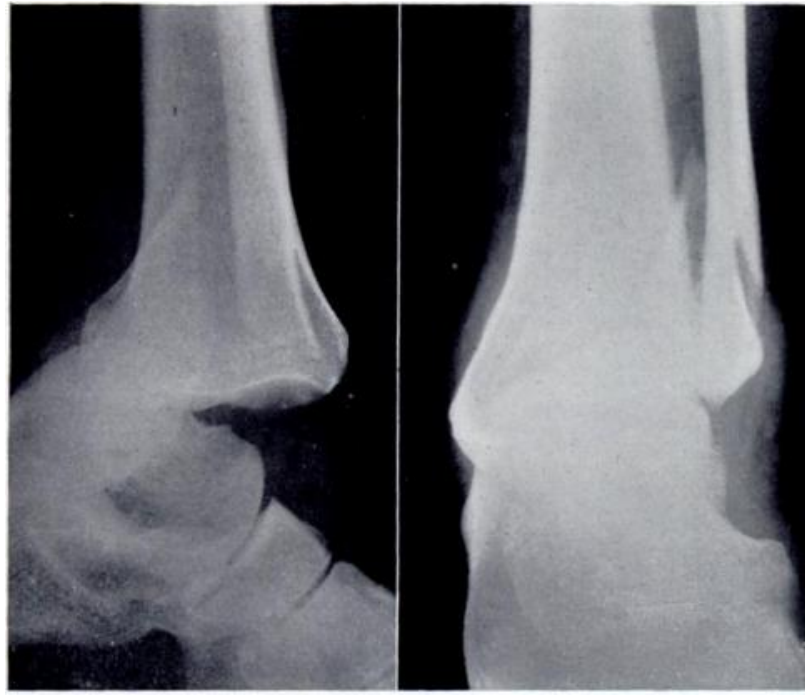

Fig. 3

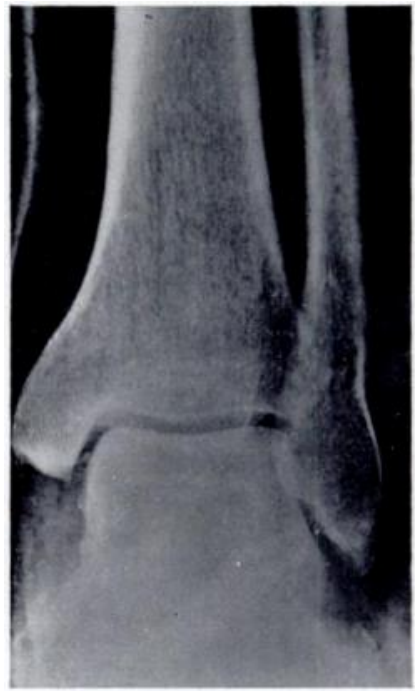

Fig. 4

Case 1. Figure 3-Initial radiograph showing a displaced oblique fibular fracture, rupture of the medial ligament and subluxation of the ankle joint. Figure 4-Radiograph in plaster showing the position in which the ankle was immobilised.

VOL. $50 \mathrm{~B}$, NO. 4, NOVEMBER 1968 


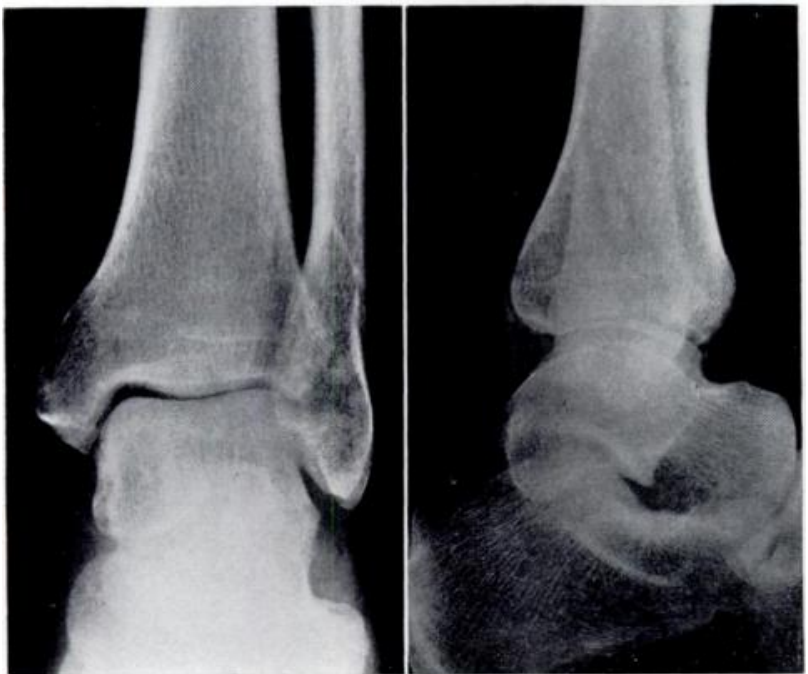

FIG. 5

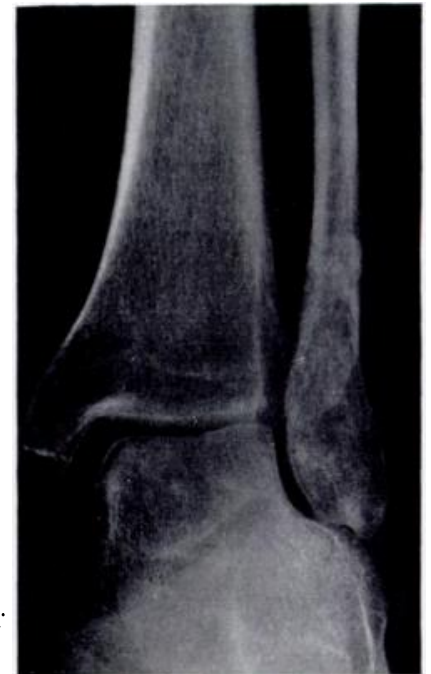

Fig. 6

Case 1. Figure 5-Radiograph taken on removal of the plaster to show the position of fibular union. Figure 6-Radiograph taken seven weeks after removal of the plaster, with recurrence of inferior tibio-fibular diastasis as shown by widening of the medial talo-malleolar space, and a stress fracture of the fibula above the united oblique fibular fracture.

was exposed and its antero-inferior extremity was found to lie at the level of the tibial articular surface. The fibres of the anterior tibio-fibular ligament attached to both proximal and distal fibular fragments were seen to be completely ruptured and the proximal part of the fibula, above the fracture, could be moved away from the tibia with ease. Figure 8 presents these findings in diagrammatic form. The fibular fracture was reduced and fixed with two anteroposterior screws inserted at an angle to the fracture according to the principles outlined by

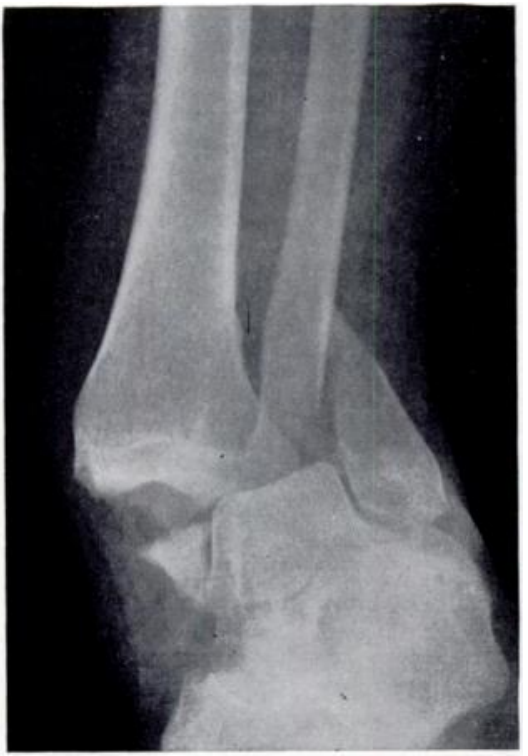

Fig. 7

Case 2-Initial radiograph showing an oblique fibular fracture, fracture of the medial malleolus and dislocation of the ankle joint.
Danis (1949) for interfragmentary compression. This produced rigid fixation of the fibular fracture. At this stage a lateral rotation-abduction strain radiograph showed clearly the presence of inferior tibio-fibular diastasis (Fig. 9). An oblique screw was therefore inserted across the inferior tibio-fibular joint (Burgess 1944, Vasli 1957). After this a medial exposure was made and the medial malleolar fracture was fixed with a single screw (Fig. 10).

Other cases-A further five cases have been seen in which, at operation, a similar low oblique fibular fracture has been found with inferior tibio-fibular diastasis (Table I). The method of fibular fixation described above has proved to be rigid, providing both interfragmentary and axial compressive forces as shown in Figure 11. In each case the oblique screw across the inferior tibio-fibular joint has been removed after eight weeks, and neither recurrence of the diastasis nor tibiofibular synostosis has been noted.

\section{DISCUSSION}

During the eighteen-month period of this investigation (1966-67) six patients have been seen with low 
oblique fibular fractures, the lowest limits of which were level with the tibial articular surface and which were associated with diastasis of the inferior tibio-fibular joint. This injury has not previously been described. Its existence has, in fact, been firmly denied (Iselin and Vellis 1961).

A further case has been found by retrospective search, in which the injury passed unrecognised. As a result the ankle deformity recurred after a period of external

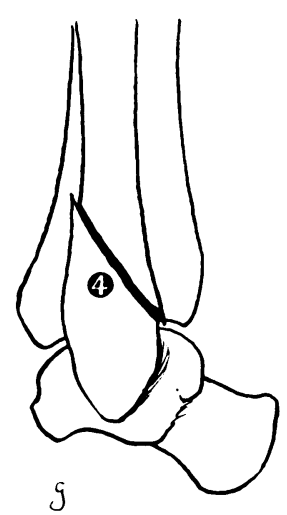

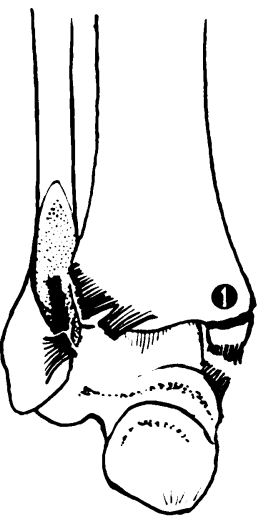

Fig. 8

Case 2-Diagram to show the ligamentous and bony lesions found in fracturediastasis of the inferior tibio-fibular joint. 1) The medial injury is either a medial malleolar fracture or a rupture of the medial ligament. 2) Complete rupture of the whole anterior tibio-fibular ligament. 3) Complete rupture of the interosseous ligament. 4) Classical mixed oblique fibular fracture. The rupture of the posterior tibio-fibular ligament was complete in five of the six cases explored.

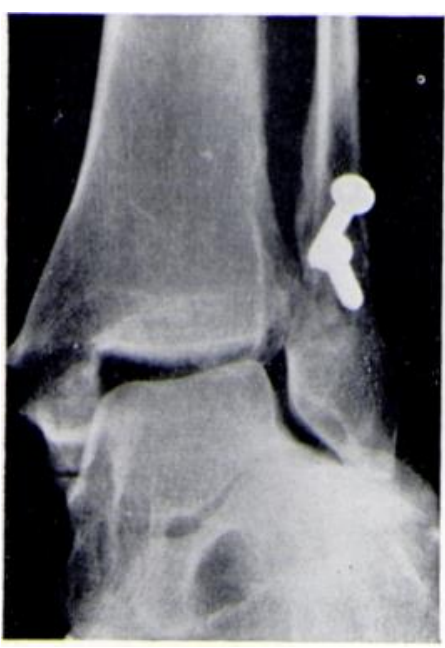

FiG. 9

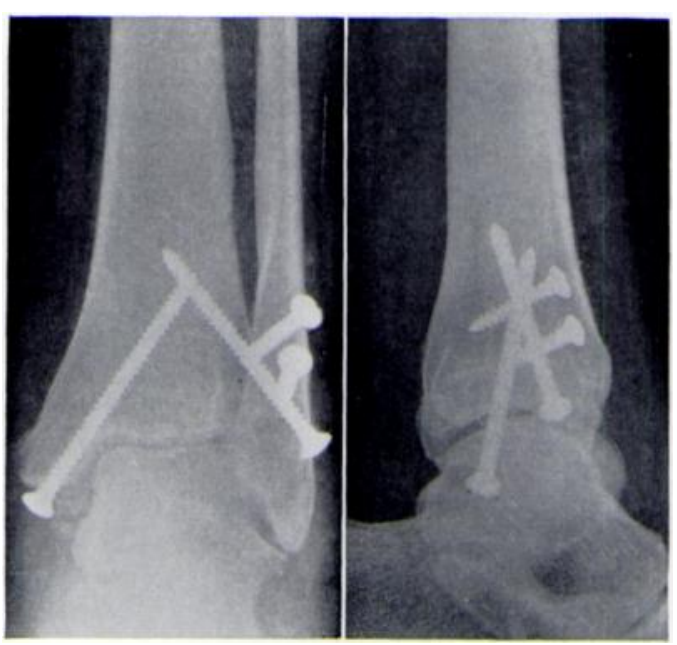

Fig. 10

Case 2. Figure 9-Strain radiograph after screw fixation of the fibular fracture alone, demonstrating lateral talar shift permitted by the total disruption of the inferior tibio-fibular joint. Only mild stress was applied for fear of disturbing fibular fixation: greater displacement was possible by lateral traction of the fibula above the fracture. Figure 10-Radiograph showing the final position after internal fixation of both sides of the ankle joint.

immobilisation. It is proposed to refer to this injury complex as fracture-diastasis of the inferior tibio-fibular joint.

All these patients had disruption of medial joint structures, three having ruptured the medial ligament and four having sustained traction fracture of the medial malleolus. It has been shown that diastasis cannot occur without medial instability (Close 1956). 
TABLE I

Radiographic and Operative Appearances in Seven Cases of Fracture-Diastasis OF THE INFERIOR TIBIO-FIBULAR JOINT

\begin{tabular}{|c|c|c|c|c|c|}
\hline $\begin{array}{c}\text { Case } \\
\text { number }\end{array}$ & $\begin{array}{c}\text { Age } \\
\text { (years) }\end{array}$ & Sex & Medial injury & Lateral injury & Remarks \\
\hline 1 & 50 & Male & $\begin{array}{l}\text { Ruptured } \\
\text { medial ligament }\end{array}$ & $\begin{array}{l}\text { Mixed oblique fibular fracture. } \\
\text { Inferior tibio-fibular diastasis }\end{array}$ & $\begin{array}{l}\text { Discovered in retrospective } \\
\text { search-syndesmosis failed to } \\
\text { heal and displacement recurred }\end{array}$ \\
\hline 2 & 47 & Female & $\begin{array}{c}\text { Fractured } \\
\text { medial malleolus }\end{array}$ & $\begin{array}{l}\text { Mixed oblique fibular fracture. } \\
\text { Inferior tibio-fibular diastasis }\end{array}$ & $\begin{array}{l}\text { Lateral injury confirmed at } \\
\text { operation and by strain } \\
\text { radiography }\end{array}$ \\
\hline 3 & 38 & Female & $\begin{array}{c}\text { Fractured } \\
\text { medial malleolus }\end{array}$ & $\begin{array}{l}\text { Mixed oblique fibular fracture. } \\
\text { Inferior tibio-fibular diastasis }\end{array}$ & $\begin{array}{c}\text { Lateral injury confirmed at } \\
\text { operation }\end{array}$ \\
\hline 4 & 23 & Male & $\begin{array}{l}\text { Ruptured } \\
\text { medial ligament }\end{array}$ & $\begin{array}{l}\text { Mixed oblique fibular fracture. } \\
\text { Inferior tibio-fibular diastasis }\end{array}$ & $\begin{array}{c}\text { Lateral injury confirmed at } \\
\text { operation }\end{array}$ \\
\hline 5 & 43 & Female & $\begin{array}{c}\text { Fractured } \\
\text { medial malleolus }\end{array}$ & $\begin{array}{l}\text { Mixed oblique fibular fracture. } \\
\text { Inferior tibio-fibular diastasis }\end{array}$ & $\begin{array}{l}\text { Lateral injury confirmed at } \\
\text { operation. Small, non-articular } \\
\text { posterior marginal tibial fracture }\end{array}$ \\
\hline 6 & 51 & Female & $\begin{array}{c}\text { Fractured } \\
\text { medial malleolus }\end{array}$ & $\begin{array}{l}\text { Mixed oblique fibular fracture. } \\
\text { Inferior tibio-fibular diastasis }\end{array}$ & $\begin{array}{l}\text { Anterior tibio-fibular injury } \\
\text { with large avulsion fracture of } \\
\text { the anterior tip of the incisura } \\
\text { fibularis (tubercle of Tillaux). } \\
\text { Confirmed at operation }\end{array}$ \\
\hline 7 & 64 & Male & $\begin{array}{c}\text { Ruptured } \\
\text { medial ligament }\end{array}$ & $\begin{array}{l}\text { Mixed oblique fibular fracture. } \\
\text { Inferior tibio-fibular diastasis }\end{array}$ & $\begin{array}{l}\text { Posterior tibio-fibular ligament } \\
\text { partially intact in its } \\
\text { proximal portion }\end{array}$ \\
\hline
\end{tabular}

During the same period fifteen patients were seen with fresh ankle injuries in which a similar mixed oblique fibular fracture was present, together with medial instability, but without inferior tibio-fibular diastasis having occurred. Radiologically the appearances of these injuries were indistinguishable from those in which fracture-diastasis was demonstrated. The diagnosis
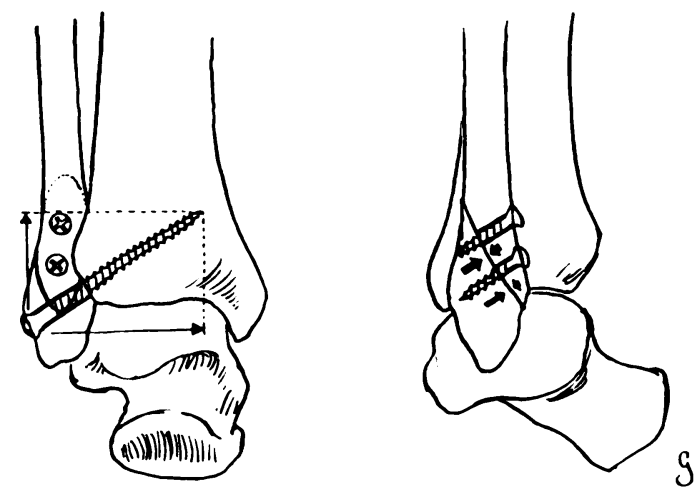

Fig. 11

Diagram to show the mechanism of the fibular fixation described. The oblique screws in the fibula produce interfragmentary compression and the vertical component of the oblique fibulo-tibial force produces axial compression.

offer a means of restoring stability to the ankle joint in the anatomical position. That there is a need for such anatomical reposition is evident when it is considered that displacement of the lower end of the fibula of the order of two to three millimetres in of fracture-diastasis of the inferior tibiofibular joint can be made only after surgical exposure of the fibular fracture.

When inferior tibio-fibular diastasis and an oblique fibular fracture occur at the same level, together with disruption of the medial osseo-ligamentous complex, the ankle is extremely unstable. If the medial injury is a rupture of the medial ligament, it can rarely, if ever, be repaired successfully. The problem of instability is greatest in these cases. The surgeon must rely on accurate reduction and adequate immobilisation of the lateral injury.

Fixation of the fibular fracture alone in such a case will leave untreated the injury of the inferior tibio-fibular joint (Fig. 9) and it would seem that the recognition of fracturediastasis, and its fixation as described above, THE JOURNAL OF BONE AND JOINT SURGERY 
a backward or lateral direction can cause considerable alteration in the mechanics of the ankle joint and predispose to osteoarthritis (Willenegger 1961).

The results of the fixation described are not presented, as the number of cases is not statistically significant. It remains the subject of further study. It was felt, however, that a description of the lesion would draw attention to an unstable ankle injury not previously described, which can result in disability due to recurrence of the deformity, unless treated correctly.

\section{SUMMARY}

1. A low oblique fracture of the fibula is described associated with diastasis of the inferior tibio-fibular joint.

2. Seven cases are presented in which this injury was seen.

3. A method of internal fixation is described.

4. The importance of recognising this injury is stressed.

I wish to express my sincere thanks to Mr A. L. Eyre-Brook, Mr H. K. Lucas, Mr A. H. C. Ratliff and Mr M. P. McCormack for their help with this study. I am also indebted to the Departments of Medical Photography and Illustration of the University of Bristol and the Royal National Orthopaedic Hospital, London, for their help in the preparation of the illustrations, and to Mrs P. Ruskin for her painstaking secretarial assistance.

\section{RIFERENCES}

Ashrurst, A. P. C., and Bromer, R. S. (1922): Classification and Mechanism of Fractures of the Leg Bones Involving the Ankle. Archives of Surgery, 4, 51.

Bonnin, J. G. (1950): Injuries to the Ankle, p. 163. London: Heinemann Medical Books Ltd.

Bosworth, D. M. (1947): Fracture-Dislocation of the Ankle with Fixed Displacement of the Fibula behind the Tibia. Journal of Bone and Joint Surgery, 29, 130.

Burgess, E. (1944): Fractures of the Ankle. Journal of Bone and Joint Surgery, 26, 721.

Burwell, H. N., and Charnley, A. D. (1965): The Treatment of Displaced Fractures at the Ankle by Rigid Internal Fixation and Early Joint Movement. Journal of Bone and Joint Surgery, 47-B, 634.

Close, J. R. (1956): Some Applications of the Functional Anatomy of the Ankle Joint. Journal of Bone and Joint Surgery, 38-A, 761.

COOPER, Sir Astley (1822): A Treatise on Dislocation and on Fractures of the Joints, p. 239. London: Longman.

Danis, R. (1949): Théorie et Pratique de l'Ostéosynthèse, p. 81. Paris: Masson et Cie.

Dupurtren (1819): Mémoire sur la Fracture de l'extrèmité infèrieure du péroné, les luxations et les accidens qui en sont la suite. Annuaire médico-chirurgical des Hopitaux et Hospices Civils de Paris, p. 1.

Iselin, M., and Vellis, H. de (1961): La primauté du péroné dans les fractures du cou-de-pied. Mémoires de l'Académie de Chirurgie, 87, 399.

Maissonneuve, J. G. (1840): Recherches sur la fracture du péroné. Archives générales de médecine, 1, 165 and 433.

Prtit, J.-L. (1726): A Treatise of the Diseases of the Bones, p. 172. London: T. Woodward.

Tillaux (reported by Gosselin) (1872): Rapports Recherches cliniques et expérimentales sur les fractures malléolaires. Bulletin de l'Académie de Médecine, Series 2, 1, 817.

VASLI, S. (1957): Operative Treatment of Ankle Fractures. Acta Chirurgica Scandinavica, Supplementum 226, p. 40.

Willenegger, H. (1961): Die Behandlung der Luxationsfrakturen des oberen Sprunggelenks nach biomechanischen Gesichtspunkten. Helvetica Chirurgica Acta, 28, 225.

Woods, R. S. (1942): Irreducible Dislocation of the Ankle-Joint. British Journal of Surgery, 29, 359.

VOl. 50 B, NO. 4, NOVEMber 1968 